\title{
Bandwidth Enhancement for Small Patch Antenna Using PBG Structure for Different Wireless Applications
}

\author{
H. F. AbuTarboush, H. S. Al-Raweshidy and R. Nilavalan \\ Wireless Networks \& Communications Centre (WNCC), School of Engineering \& Design, \\ Brunel University, West London, UK.
}

Email: Hattan.AbuTarboush@brunel.ac.uk

\begin{abstract}
A design strategy using Photonic Band Gap (PBG) structure on ground plane to achieve wider bandwidth for patch antenna is presented. It is found that, the impedance bandwidth has improved from $3.72 \%$ to 31.9 $\%$ at centre frequency $9 \mathrm{GHz}$ after adding PBG on the ground plane. The antenna has multi band operations at 5, 6 and $9 \mathrm{GHz}$. E-Plane and H-plane radiation patter is satisfied within this bands.
\end{abstract}

\section{INTRODUCTION}

The use of Photonic Band Gap (PBG) structure is becoming attractive for many researchers in electromagnetic and antenna field. PBG had been used to improve the performance of various antennas such as patch antenna and resonant antenna. Microstrip patch antenna is promising to be a good candidate for future wireless technologies. Microstrip patch antenna consists of a dielectric substrate, with a ground plane on the other side. Due to its advantages such as low weight, low profile planar configuration, low fabrication costs and capability to integrate with microwave integrated circuits technology, the microstrip patch antenna is very well suited for applications such as wireless communications system, cellular phones, pagers, Radar systems and satellite communications systems [1, 2, 3].

Electromagnetic Band Gap (EBG) or Photonic Band Gap (PBG) materials are periodic dielectrics, which can stop the propagation of electromagnetic waves in certain directions, within certain frequency bands [4]. Several types of EBG or PBG substrates have been investigated [5]. It has been reported that EBG or PBG materials used with microstrip patch antennas can improve their radiation patterns, increase their gain, and reduce the side lobe and back lobe levels [6]. Also, some research has been reported on improving the antenna bandwidth by using PBG [7, 8]. PBG has been used in the ground plane to improve the bandwidth [9].

In this paper, a compact multiband design of Microstrip patch antenna using a PBG slot on the ground plane is proposed. The bandwidth has improved by adding the PBG slots. The paper is divided as follows: section two, presents the dimensions of the proposed antenna followed by the result of the simulated return loss and the radiation pattern for the operation frequencies. Finally, section three presents the conclusion. Results are based on a commercially available finite element package HFSS V.11.

\section{ANTENNA DESIGN \& RESULTS}

The antenna has a very simple structure fed by microstrip line. Figure 1 and table 1 demonstrate the dimensions of the antenna. Generally the overall dimensions of the antenna is $70 \mathrm{~mm}$ by $30 \mathrm{~mm}$, the selected substrate for this structure is Roger RT/duroid 5880 with dielectric constant 2.2. In order to improve the impedance bandwidth performance for the antenna, a PBG structure has been placed on the ground plane instead an ordinary ground plane with radius of $4 \mathrm{~mm}$ and distance between each radius $2 \mathrm{~mm}$. Surface wave will be reduced and that resulted in increasing the bandwidth of the antenna as can be seen in figure 2. HFSS package is used to obtain the return loss and the radiation pattern. 


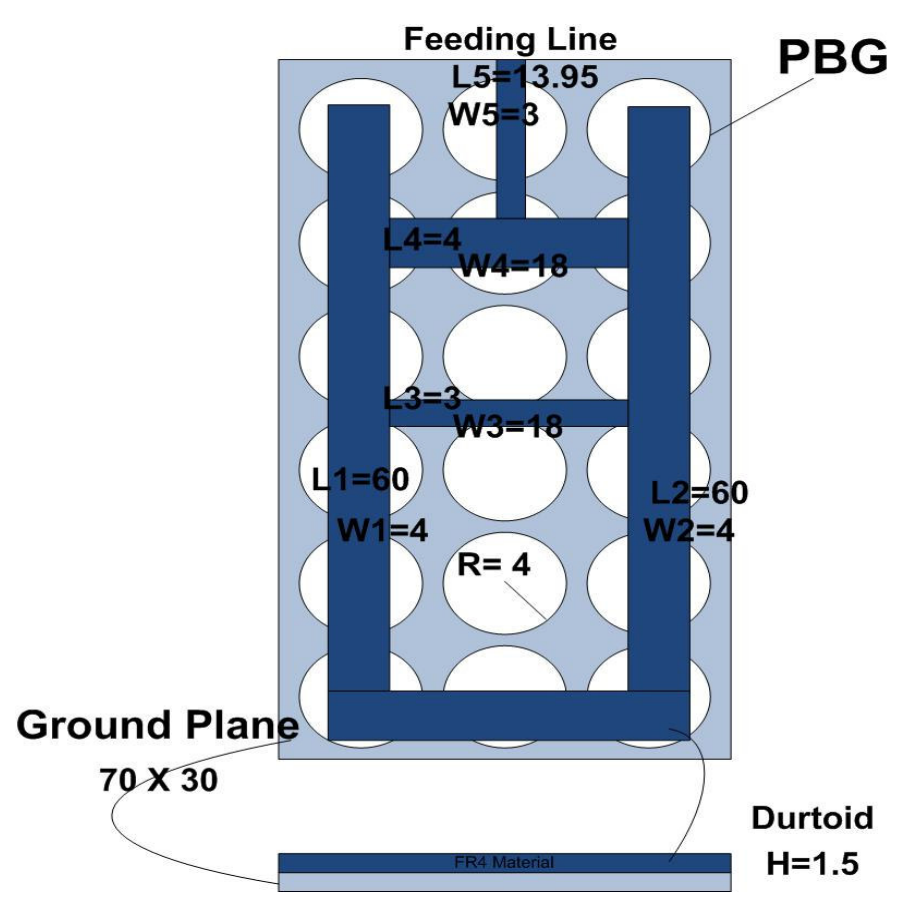

Fig. 1Geometry and diminutions of the antenna

Tab.1 The dimensions of the antenna (mm).

\begin{tabular}{|c|c|c|c|c|c|c|c|c|c|c|}
\hline W1 & L1 & W2 & L2 & W3 & L3 & W4 & L4 & W5 & L5 & R \\
\hline 4 & 60 & 4 & 60 & 18 & 3 & 18 & 4 & 3 & 14 & 4 \\
\hline
\end{tabular}

From figure 2, it can be seen that the proposed antenna before adding PBG has two bands operation at $5 \mathrm{GHz}$ and 9 $\mathrm{GHz}$ with $2.67 \%$ and $3.72 \%$ impedance bandwidth respectively. Whereas after placing the PBG in the ground plane the impedance bandwidth has increased at 5, 6 and $9 \mathrm{GHz}$ with 5.5\%, 5.9\% and 31.9\% respectively as shown figure 1 and table 2 .

Tab.2 Comparison between bandwidth with and without PBG on the ground plane

\begin{tabular}{|c|c|c|}
\hline Frequency band & Bandwidth without PBG & Bandwidth with PBG \\
\hline $5 \mathrm{GHz}$ & $2.76 \%$ & $5.5 \%$ \\
\hline $6 \mathrm{GHz}$ & $0 \%$ & $5.9 \%$ \\
\hline $9 \mathrm{GHz}$ & $3.72 \%$ & $31.95 \%$ \\
\hline
\end{tabular}




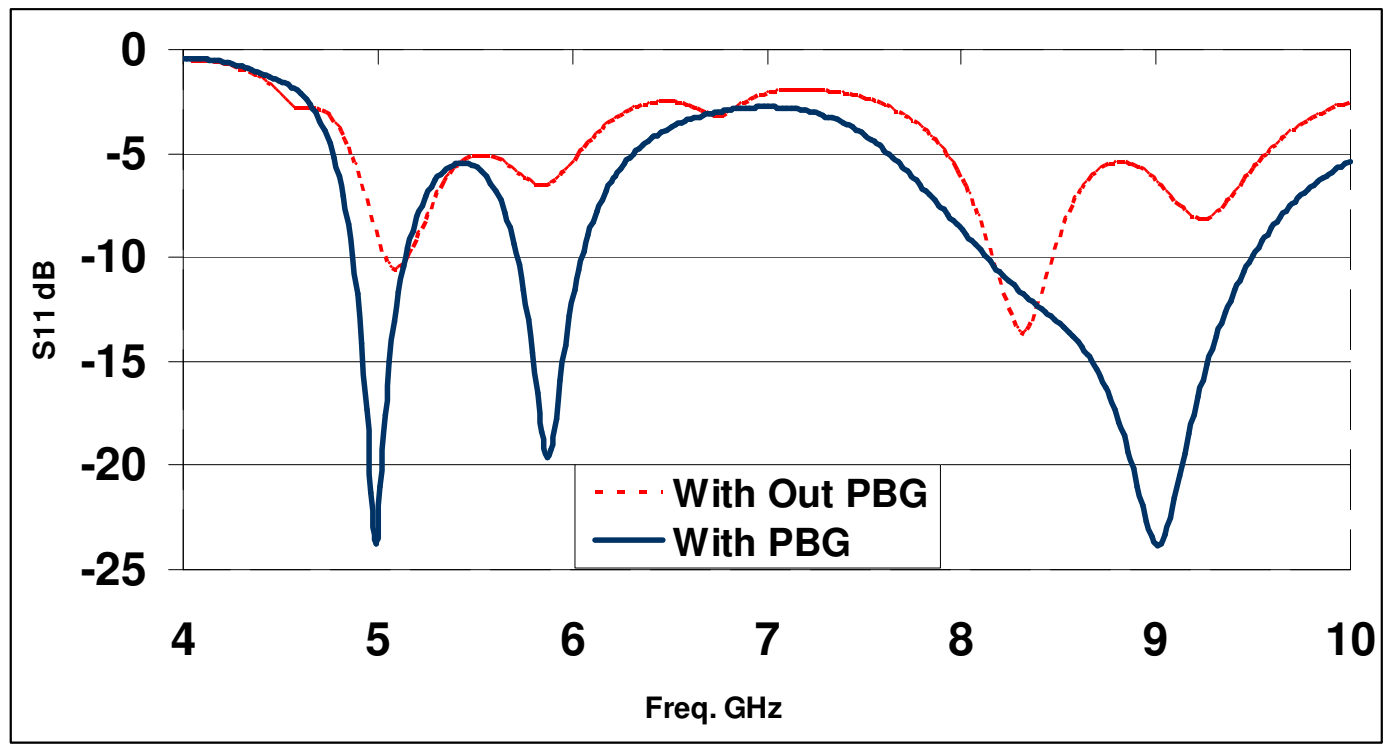

Fig. 2 Return loss response of the proposed antenna with and without PBG
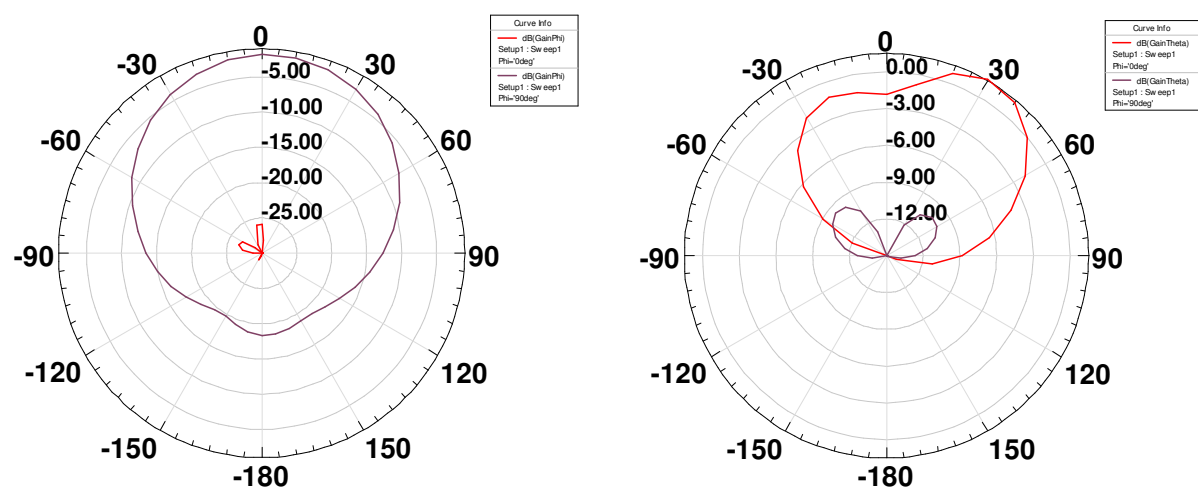

5 GHz Phi

5 GHz Theta

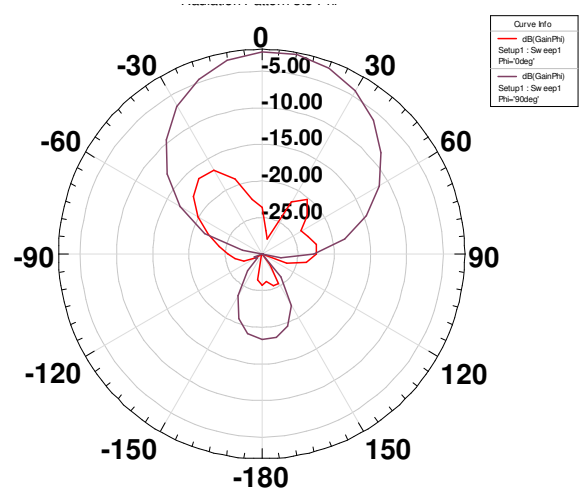

8.5 GHz Phi

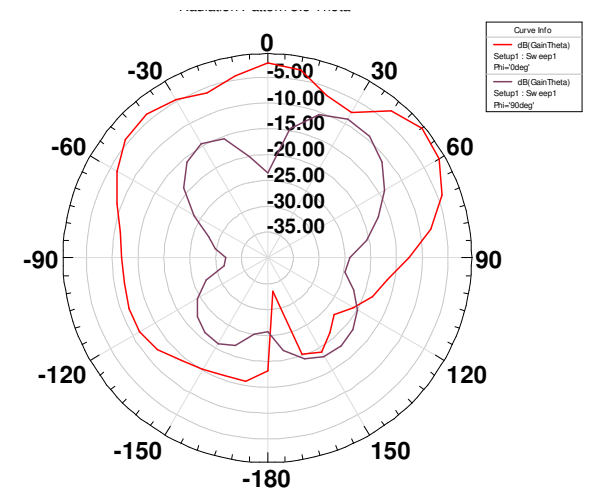

8.5 GHz Theta 


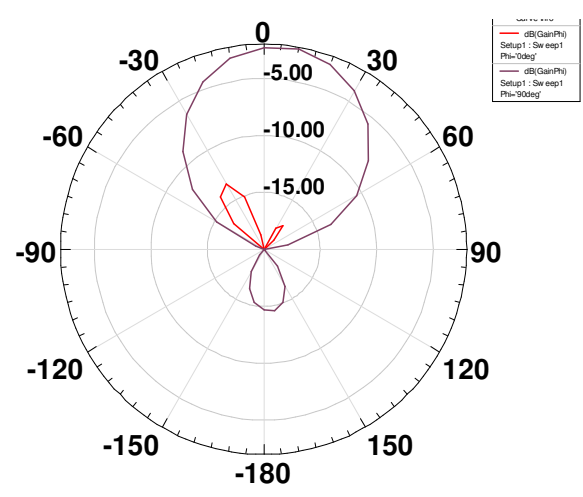

9 GHz Phi

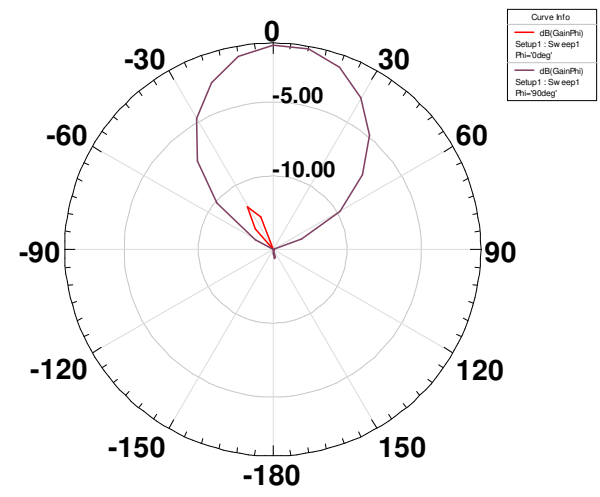

9.5 GHz Phi

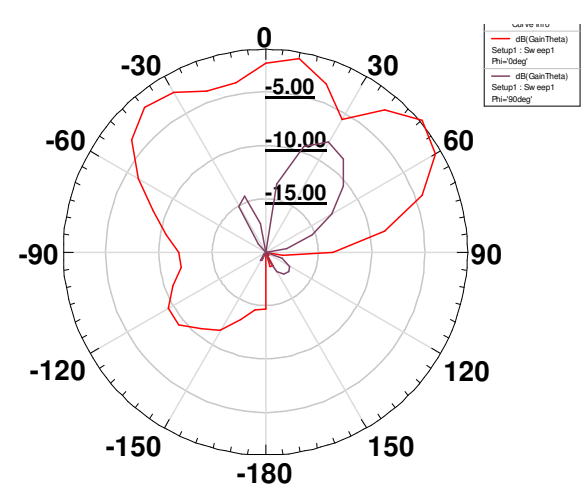

$9 \mathrm{GHz}$ Theta

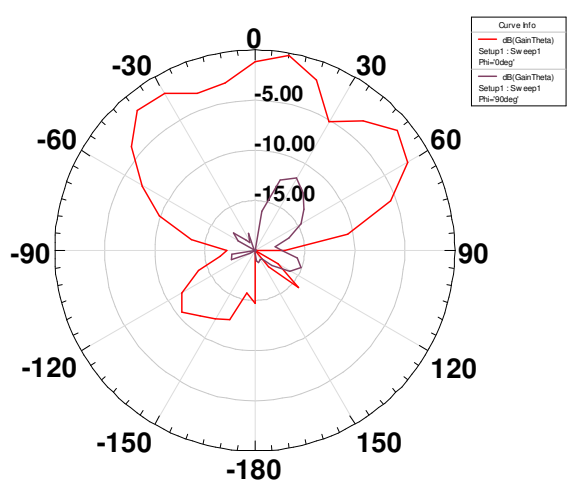

9.5 GHz Theta

Fig. 3 E-plane and H-plane radiation pattern for the antenna at different frequencies 5, 8.5, 9 and 9.5 GHz.

\section{CONCLUSION}

A PBG structure in ground plane is shown to improve the impedance bandwidth from $3.72 \%$ to $31.9 \%$ comparing to a conventional patch antenna. The overall size for the antenna is $70 \times 30 \mathrm{~mm}$. The radiation patterns at 5, 8.5, 9 and 9.5 $\mathrm{GHz}$ have been provided. This antenna can be used in various wireless communication systems.

\section{REFERENCES}

[1] W.L. Stutzman and G.A. Thiele, Antenna Theory and Design, 2nd ed. New York: Wiley, 1998.

[2] C.A. Balanis, Antenna Theory, 2nd ed. New York: John Wiley \& Sons, Inc., 1997.

[3] H. F. AbuTarboush, H. S. Al-Raweshidy, "A Connected E-Shape and U-Shape Dual-Band Patch Antenna for Different Wireless Applications", the Second International EURASIP Workshop on RFID Technology, July, 2008.

[4] Joannopoulos, J.D., Meade, R.D., and Winn, J.N.: 'Photonic crystals molding the flow of light' (Princeton University Press, Princeton, NJ, 1995).

[5] Sharma, S.K., and Shafai, L.: 'Enhanced performance of an aperturecoupled rectangular microstrip antenna on a simplified unipolar compact photonic bandgap (UC-PBG) structure'. Proc. IEEE Symp. on Antennas and Propagation, July 2001, Vol. 2, pp. 8-13.

[6] Qian, Y., Sievenpiper, D., Radisic, V., Yablonovitch, E., and Itoh, T.: 'A novel approach for gain and bandwidth enhancement of patch antennas'. Proc. IEEE Radio and Wireless Conf., RAWCON98, Aug. 1998, pp. 221-224.

[7] Rahman, M., and Stuchly, M.A.: 'Wide-band microstrip patch antenna with planar PBG structure'. Proc. IEEE Symp. on Antennas and Propagation, 8-13 July 2001, Vol. 2, pp. 486-489. 